\title{
Transgenic Mice Expressing Soluble Tumor Necrosis Factor-Receptor are Protected Against Bone Loss Caused by Estrogen Deficiency
}

\author{
Patrick Ammann, ${ }^{\star}$ René Rizzoli,, Jean-Philippe Bonjour, ${ }^{\star}$ Sandrine Bourrin, ${ }^{\star}$ Jean-Marc Meyer, ${ }^{\ddagger}$ Pierre Vassalli, ${ }^{\S}$ \\ and Irène Garcia $\$$ \\ *Division of Clinical Pathophysiology, WHO Collaborating Center for Osteoporosis and Bone Diseases, Department of Internal \\ Medicine, University Hospital; ${ }^{\S}$ Department of Pathology, and ${ }^{\ddagger}$ School of Dentistry, University of Geneva, Geneva, Switzerland
}

\begin{abstract}
To evaluate the role of tumor necrosis factor $(\mathrm{TNF} \alpha)$ in bone loss resulting from estrogen deficiency, the effects of ovariectomy were explored in six-month-old transgenic mice expressing high blood levels of a soluble TNF receptor type I (sTNFR1)-FcIgG3 fusion protein, which neutralizes $\mathrm{TNF} \alpha$, and in their nontransgenic littermates used as controls. These transgenic mice were identical to control mice in bone mass (evaluated by bone mineral density and content) and strength. 12 weeks after ovariectomy, the decrease in bone mass and increase in osteocalcin (marker of bone turnover) found in control mice were not observed in transgenic mice, which were not different from sham-operated mice, transgenic or not. This observation suggests a critical role for TNF $\alpha$ in the pathogenesis of bone loss induced by estrogen deficiency, a common cause of morbidity in postmenopausal women. (J. Clin. Invest. 1997. 99:1699-1703.) Key words: osteoporosis - pathophysiology • DXA • osteocalcin • biomechanics
\end{abstract}

\section{Introduction}

Estrogen deficiency increases the rate of bone remodeling and leads to an imbalance between bone resorption and formation, resulting into net bone loss and osteoporosis. However, the exact pathogenesis of postmenopausal osteoporosis, which represents one of the most severe causes of morbidity in aged women, is still not fully understood. Cytokines like interleukin-1 (IL-1), tumor necrosis factor- $\alpha$ (TNF $\alpha)$, interleukin-6 (IL-6), interleukin-11 (IL-11), and macrophage colony stimulating factor $(\mathrm{M}-\mathrm{CSF})^{1}$ may be involved in bone resorption by facilitating the recruitment and maturation of osteoclast precursors. Indirect evidence suggests that $\mathrm{TNF} \alpha$ and IL-1, which both stimulate bone resorption in vitro $(1,2)$ and in vivo $(3)$, might be involved in the initial step leading to bone loss in-

Address correspondence to P. Ammann, M.D., Division of Bone Diseases (formerly of Clinical Pathophysiology), Department of Internal Medicine, University Hospital, CH-1211 Geneva 14, Switzerland. Phone: 41-22-38-29-950; FAX: 41-22-38-29-973.

Received for publication 17 July 1996 and accepted in revised form 14 January 1997

1. Abbreviations used in this paper: $\mathrm{BMD}$, bone mineral density; $\mathrm{BMC}$, bone mineral content; M-CSF, macrophage colony stimulating factor.

J. Clin. Invest.

(C) The American Society for Clinical Investigation, Inc.

0021-9738/97/04/1699/05 \$2.00

Volume 99, Number 7, April 1997, 1699-1703 duced by estrogen deficiency (3-14). TNF $\alpha$ and IL-1 are produced in increased amounts in vitro by peripheral blood monocytes of ovariectomized patients (15-17) and by bonemarrow cells of ovariectomized rats (18), an effect antagonized by estrogen replacement therapy. This suggests that estrogens modulate the production of these cytokines and that estrogen deficiency might result in their increase and thus in enhanced bone resorption.

Recently, a model of transgenic mice in which the activity of TNF $\alpha$ is permanently prevented by the constitutive presence of high levels of circulating soluble TNF $\alpha$-receptor1 (sTNFR1) has been described (19). In these mice, a transgene coding for a human sTNFR1-IgG3Fc fusion protein has been placed under the control of an alpha1-anti-trypsin (AAT) promoter, leading to synthesis in the liver and release in the plasma of high amounts of the fusion protein (19). These mice showed an apparent complete neutralization of the systemic TNF and were protected from lethal septic shock and cerebral malaria. In contrast, they were highly sensitive to Listeria monocytogenes and Leishmania major infections (19).

To evaluate the role of TNF in bone loss resulting from estrogen deficiency, the effects of ovariectomy were explored in TNF-R1 transgenic mice and in their nontransgenic littermates used as controls. 12 weeks after ovariectomy, the decrease in bone mass and increase in bone turnover found in control mice were not observed in transgenic mice. This observation suggests a critical role for TNF $\alpha$ in the pathogenesis of bone loss induced by estrogen deficiency.

\section{Methods}

Animal. Transgenic mice expressing a soluble TNF-R1 fusion protein were generated as previously described (19). In the present study, a transgenic line (progeny of a founder AAT-sTNFR1-IgG3Fc transgenic mouse on a Balb/c background) expressing serum levels of $50-100 \mu \mathrm{g} / \mathrm{ml}$ of the fusion protein was used; littermate mice negative for the transgene, which have otherwise an identical genetical background, were used as controls. Mice were kept in cages of five, at $25^{\circ} \mathrm{C}$ with a $12 / 12 \mathrm{~h}$ light/dark cycle; they had free access to a diet (Kliba Mühle, Kaiseraugst, Switzerland) containing $0.8 \%$ phosphorus and $1.1 \%$ calcium during the whole experiment. At the age of $6 \mathrm{mo}$, ovariectomy or sham-operation were performed by dorsal approach under anesthesia induced by the intraperitoneal injection of ketamine hydrochloride $(100 \mathrm{mg} / \mathrm{kg}$ body weight). All experimental designs and procedures have received the approval of the Animal Ethics Committee of the University of Geneva Faculty of Medicine.

Bone mass measurements by dual energy $x$-ray absorptiometry $(D X A)$. Techniques measuring bone mineral content (BMC) and bone mineral density (BMD) by dual energy x-ray absorptiometry $(20,21)$ with a Hologic QDR-1000 instrument (Waltham, MA), were adapted for application in the mouse. An ultra high resolution mode (line spacing $0.0254 \mathrm{~cm}$ and resolution $0.0127 \mathrm{~cm}$ ) was used with a collimator of $0.09 \mathrm{~cm}$ diameter. During the measurements, the animals were anesthetized with ketamine hydrochloride and were lying on the 
back with the posterior legs maintained in external rotation with a tape. The hip, knee, and ankle articulations were in $90^{\circ}$ flexion. Bone mineral content (BMC), bone mineral density (BMD) and scanned area were recorded at the level of the right tibia. To take into account possible differences in the local proportion of trabecular and cortical bone, the total tibia was divided into three equal regions. The proximal tibia corresponded to the region containing the largest proportion of trabecular bone, the midshaft was essentially formed by cortical bone. To evaluate accuracy, BMC of 12 tibias was measured in situ. Then, bones were isolated and ashed at $800^{\circ} \mathrm{C}$. Calcium content in the ashes was determined. Highly significant linear regression was found between in situ BMC measurements and chemically determined calcium content $(y=-6.09+0.72 x ; r 2=0.928 ; P<0.0001)$. The influence of soft tissue modification was also evaluated by measuring tibia BMC/BMD under different thicknesses of muscle. This did not significantly influence BMC/BMD values (data not shown). The in vivo reproducibility was evaluated by measuring the coefficient of variation $(\mathrm{CV}=100 \times \mathrm{SD} /$ mean $)$ of three BMD measurements in six mice, each time with repositioning of the animal. CV was $1.4 \%$ for the total tibia, $1.9 \%$ for the proximal tibia and $2.5 \%$ for the midshaft tibia. The stability of the measurement was controlled by scanning a phantom every week. The proximal tibia was selected for determination of bone mass, since it appeared to be particularly sensitive to estrogen deficiency (see Table II), probably due to its high proportion of trabecular bone. Measures of BMC and BMD have the advantage of evaluating bone mass as an end point parameter, thus integrating various alterations in bone turnover.

Bone mechanical properties measurement. Bone mechanical properties were evaluated at the level of the midshaft tibia using a threepoint bending test (21). Tibia were excised and kept frozen at $-20^{\circ} \mathrm{C}$. Before mechanical testing, tibia were slowly thawed and then maintained immersed in physiological solution. The tibia was then placed in material testing machine on two supports separated by a distance of $8 \mathrm{~mm}$ and load was applied on the middle of the shaft. The mechanical resistance to failure was tested using a servo-controlled electromechanical system (Instron Corp., High Wycombe, England). The actuator was displaced at a rate of $2 \mathrm{~mm} / \mathrm{min}$. Both displacement and load were recorded. Ultimate strength (maximal load) and stiffness (slope of the linear part of the curve, representing the elastic deformation) were calculated. The reproducibility was evaluated by measuring the coefficient of variation $(\mathrm{CV})$ between pairs of right and left tibia. CV was $2.6 \pm 0.5 \%(n=3$ pairs $)$. A close relation between bone mass of the midshaft tibia as evaluated by in vivo DXA and biomechanics was found $(y=923 x+10.23 ; r 2=0.458, P=0.008)$.

Bone histomorphometry. The proximal tibial metaphyses were fixed, dehydrated and embedded undecalcified in a methylmethacrylate-based solution, as previously described (22). For each bone specimen, eight $7 \mu \mathrm{M}$ thick longitudinal frontal sections were obtained us- ing a Leica Polycut E microtome (Leica, France) equipped with tungsten carbide $50^{\circ}$ knifes. Sections were stained with Goldner's trichrome. The histomorphometric analysis was performed with a Leica Quantimet Q570 color image processor equipped with a Sony 930 camera coupled to a Leitz DM/RBE microscope. Measurements were done on 8 sections per specimen at a magnification of $\times 25$, at the level of the secondary spongiosa. This area is located under the longitudinal bone growth area, or primary spongiosa.

Standardized terms and abbreviations are used, according to the American Society for Bone and Mineral Research histomorphometry nomenclature (23): BV/TV (expressed in percent), trabecular bone volume / tissue volume, corresponding to the amount of trabecular bone within the cancellous space; Tb. Th. (expressed in $\mu \mathrm{m}$ ), mean thickness of the trabeculae; Tb. N. (expressed $/ \mathrm{mm}$ ) = mean number of trabeculae; $\mathrm{Tb}$. Sp. (expressed in $\mu \mathrm{m})=$ trabecular separation, estimating the distance between two trabeculae.

The last three parameters reflect the spatial distribution of trabeculae and are derived from surface to volume ratio (BS/BV) measurements according to stereologic formulae proposed by Parfitt (24).

Biology. Plasma osteocalcin was determined by radioimmunoassay with reagents of Biomedical Technologies (Stoughton, MA). Plasma calcium and phosphate levels were measured by atomic spectrophotometry and by a colorimetric assay described by Chen (25), respectively.

Statistics. Significance of difference between the groups was evaluated with an analysis of variance (ANOVA). When appropriate, a two sided Student's $t$ test was performed. Histomorphometric results were compared using a non-parametric Kruskal-Wallis test.

\section{Results}

Expression of high levels of soluble TNFR-IgG3 fusion protein does not modify bone metabolism in intact mice. At 6 mo of age, transgenic mice and their littermate controls were comparable in body weight, bone size, bone mass as evaluated by BMD/ BMC measurements, bone strength as assessed by a threepoint bending test, and bone turnover as evaluated by serum osteocalcin levels (Table I). Stability of the BMD values observed in transgenic and control mice over 3 mo of observation indicated the maturity of the skeleton and ruled out major influences of the transgene expression on skeletal development (Fig. 1, Table II).

Expression of high levels of soluble TNFR-IgG3 fusion protein protects against ovariectomy-induced bone loss. Ovariectomy performed at 6 mo of age was followed in control mice

Table I. Characteristics of Control and Transgenic Mice at 6 mo of Age

\begin{tabular}{|c|c|c|c|c|c|c|}
\hline & Mice & & Control & & Transgenic & \\
\hline & Body weight & grams & $27.3 \pm 0.54$ & (7) & $28.0 \pm 0.5$ & (6) \\
\hline \multirow[t]{4}{*}{ Plasma } & sTNFR1-FclgG3 & $\mathrm{ng} / \mathrm{ml}$ & $<5$ & $(7)$ & 50000 & (6) \\
\hline & Osteocalcin & $\mathrm{ng} / \mathrm{ml}$ & $128.3 \pm 12.3$ & (6) & $135.9 \pm 8.7$ & (6) \\
\hline & Calcium & $\mathrm{mmol} / \mathrm{l}$ & $2.15 \pm 0.04$ & (6) & $2.17 \pm 0.05$ & (6) \\
\hline & Phosphate & $\mathrm{mmol} / 1$ & $2.51 \pm 0.11$ & (6) & $2.58 \pm 0.07$ & (6) \\
\hline Tibia & AREA & $\mathrm{cm}^{2}$ & $0.1816 \pm 0.0043$ & (7) & $0.1819 \pm 0.0056$ & (6) \\
\hline \multirow[t]{2}{*}{ DXA measurements } & $\mathrm{BMC}$ & $\mathrm{mg}$ & $20.5 \pm 0.6$ & $(7)$ & $20.4 \pm 0.8$ & (6) \\
\hline & BMD & $\mathrm{mg} / \mathrm{cm}^{2}$ & $113.7 \pm 1.1$ & (7) & $111.2 \pm 1.5$ & (6) \\
\hline Tibia & Ultimate strength & $\mathrm{N}$ & $14.84 \pm 0.76$ & (4) & $14.97 \pm 0.69$ & (4) \\
\hline Biomechanics & Stiffness & $\mathrm{N} * \mathrm{~mm}$ & $1.33 \pm 0.14$ & (4) & $1.15 \pm 0.15$ & (4) \\
\hline
\end{tabular}

Values are means \pm SEM (n) and were obtained in intact control and transgenic mice. 
Control Mice

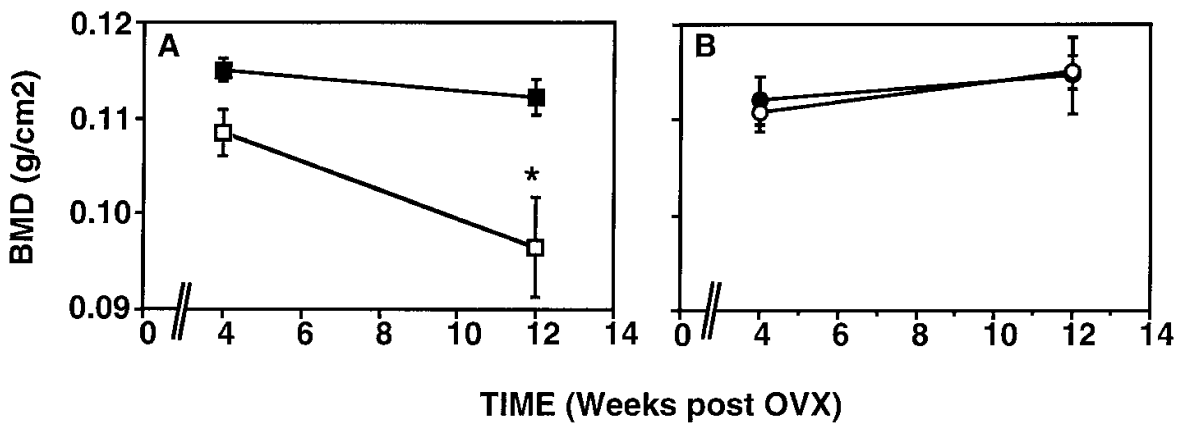

Transgenic Mice

Figure 1. Proximal tibia BMD $\left(\mathrm{g} / \mathrm{cm}^{2}\right)$ measured in 6-mo-old sham-operated (closed symbols) and ovariectomized (open symbols) mice. $A$ represents values obtained in control mice and $B$ in transgenic mice. Values of duplicate measurements are means \pm SEM, $n=5-6$. Significance of difference between groups was evaluated with an analysis of variance (ANOVA); $* P<0.001$. with a time-dependent decrease in the bone mass of the tibia, already detectable after 4 wk (Fig. 1); after 12 wk, these mice displayed a significant decrease $(P<0.01)$ of proximal tibia BMD compared with sham-operated control mice (Table II and Fig. 1). Decrease in BMD of total tibia was of lower magnitude, although still significant $(P<0.05)$; this could be explained by the fact that BMD of cortical bone was not altered, as seen by examination of the midshaft tibia (Table I). In contrast, ovariectomized transgenic mice did not display any bone loss during this period of time (Table II and Fig. 1) compared with sham-operated transgenic mice $(P<0.01)$.

The bone mass decrease in ovariectomized control mice was also demonstrated by histomorphometric analysis as evaluated at the level of secondary spongiosa of proximal tibia sections of specimens collected 14 wk after ovariectomy or shamoperation. A significant decrease in bone volume, trabeculae number, and an increase in trabeculae separation were detected (Table III). However, there was no significant difference between sections from control mice, sham-operated and ovariectomized transgenic mice. The slight lower trabecular bone volume in transgenic sham-operated than in control mice did not reach a level of statistical significance. Osteocalcin levels, which reflect bone turnover, were increased 12 weeks after ovariectomy in control mice, but not in transgenic mice, in which they were on the contrary slightly decreased; this variation was not significant (Fig. 2).

\section{Discussion}

The present study demonstrates that the expression of soluble $\mathrm{TNF}$ receptor, neutralizing $\mathrm{TNF} \alpha$, protects mice from bone loss caused by estrogen deficiency. These observations suggest that $\mathrm{TNF} \alpha$ alone is required for the induction of permanent bone loss resulting from estrogen deficiency. This conclusion must be evaluated in the light of other experimental evidence indicating a role for IL-1 and IL-6 in this condition. Recent studies using mutant mice with IL-1 $\beta$ gene deletion suggest that IL-1 $\beta$ is not required for post ovariectomy bone loss (26), but they do not exclude a role for IL- $1 \alpha$. Furthermore, administration of IL-1 receptor antagonist caused an incomplete prevention of rapid bone loss early after ovariectomy, but full prevention was achieved during this period only by the simul-

Table II. Effects of Ovariectomy on Bone Mineral Density in Control or Transgenic Mice

\begin{tabular}{|c|c|c|c|c|c|}
\hline \multirow[b]{2}{*}{ Time after ovariectomy } & & \multicolumn{2}{|c|}{$4 \mathrm{wk}$} & \multicolumn{2}{|c|}{$12 \mathrm{wk}$} \\
\hline & & SHAM & ovx & SHAM & ovx \\
\hline \multicolumn{6}{|l|}{ Total tibia } \\
\hline Control & $\begin{array}{c}\left(\mathrm{g} / \mathrm{cm}^{2}\right) \\
(\%)\end{array}$ & $0.1137 \pm 0.0011$ & $\begin{array}{c}0.1103 \pm 0.0008 \\
-3.0 \pm 1.2\end{array}$ & $0.1112 \pm 0.0005$ & $\begin{array}{c}0.1060 \pm 0.0017 \\
4.8 \pm 1.6^{*}\end{array}$ \\
\hline Transgenic & $\begin{array}{c}\left(\mathrm{g} / \mathrm{cm}^{2}\right) \\
(\%)\end{array}$ & $0.1112 \pm 0.0015$ & $\begin{array}{c}0.1113 \pm 0.0007 \\
0.1 \pm 1.5\end{array}$ & $0.1086 \pm 0.0013$ & $\begin{array}{c}0.1073 \pm 0.0010 \\
-1.2 \pm 1.5\end{array}$ \\
\hline \multicolumn{6}{|l|}{ Proximal tibia } \\
\hline Control & $\begin{array}{c}\left(\mathrm{g} / \mathrm{cm}^{2}\right) \\
(\%)\end{array}$ & $0.1146 \pm 0.0011$ & $\begin{array}{c}0.1085 \pm 0.0020 \\
-5.4 \pm 2.0^{*}\end{array}$ & $0.1121 \pm 0.0019$ & $\begin{array}{c}0.0965 \pm 0.0052^{\ddagger} \\
-14.0 \pm 4.9^{*}\end{array}$ \\
\hline Transgenic & $\begin{array}{c}\left(\mathrm{g} / \mathrm{cm}^{2}\right) \\
(\%)\end{array}$ & $0.1120 \pm 0.0025$ & $\begin{array}{c}0.1094 \pm 0.0021 \\
-2.3 \pm 2.9\end{array}$ & $0.1146 \pm 0.0040$ & $\begin{array}{c}0.1150 \pm 0.0018 \\
0.4 \pm 3.8\end{array}$ \\
\hline \multicolumn{6}{|l|}{ Midshaft tibia } \\
\hline Control & $\begin{array}{c}\left(\mathrm{g} / \mathrm{cm}^{2}\right) \\
(\%)\end{array}$ & $0.1061 \pm 0.0012$ & $\begin{array}{c}0.1046 \pm 0.0014 \\
-1.5 \pm 1.7\end{array}$ & $0.1049 \pm 0.0012$ & $\begin{array}{c}0.1019 \pm 0.0015 \\
-2.9 \pm 1.8\end{array}$ \\
\hline Transgenic & $\begin{array}{c}\left(\mathrm{g} / \mathrm{cm}^{2}\right) \\
(\%)\end{array}$ & $0.1038 \pm 0.0032$ & $\begin{array}{c}0.1052 \pm 0.0012 \\
1.4 \pm 3.3\end{array}$ & $0.9750 \pm 0.0024$ & $\begin{array}{c}0.9600 \pm 0.0015 \\
-1.5 \pm 2.9\end{array}$ \\
\hline
\end{tabular}

Values are means \pm SEM and represent BMD $\left(\mathrm{g} / \mathrm{cm}^{2}\right)$ or the difference of BMD (expressed in percent of SHAM) between SHAM $(n=6)$ and ovariectomized mice (OVX; $n=5)$. ${ }^{*} P<0.05$ between control and transgenic mice as evaluated by a two-sided Student's $t$ test. ${ }^{*} P<0.05$ between control and transgenic mice ( 4 and $12 \mathrm{wk}$ after OVX) as evaluated by a variance analysis ANOVA. 
Table III. Effects of Ovariectomy on Histomorphometrical Variables in Control or Transgenic Mice

\begin{tabular}{lllcc}
\hline & & & \multicolumn{1}{c}{ Sham } & Ovariectomized \\
\hline BV/TV & \multirow{2}{*}{ (\%) } & Control & $3.32 \pm 0.54$ & $1.57 \pm 0.18^{\ddagger}$ \\
& & Transgenic & $2.45 \pm 0.83$ & $2.02 \pm 0.21$ \\
TB. N/mm & & Control & $1.41 \pm 0.13$ & $0.60 \pm 0.10^{\ddagger}$ \\
& & Transgenic & $1.10 \pm 0.25$ & $0.76 \pm 0.07$ \\
Tb. Sp. & $(\mu \mathrm{M})$ & Control & $703.0 \pm 68.0$ & $1837.4 \pm 305.1^{*}$ \\
& & Transgenic & $1093.0 \pm 323.3$ & $1323.4 \pm 111.2$ \\
Tb. Th. & $(\mu \mathrm{m})$ & Control & $23.50 \pm 1.85$ & $27.20 \pm 1.71$ \\
& & Transgenic & $23.50 \pm 1.55$ & $26.60 \pm 1.21$
\end{tabular}

Values are means \pm SEM. BV/TV, TB. N, Tb. Sp. and Tb. Th. were evaluated $14 \mathrm{wk}$ after ovariectomy at the level of the secondary spongiosa of the proximal tibia in sham $(n=4)$ and ovariectomized $(n=5)$ transgenic and control mice. ${ }^{*} P<0.01$ and ${ }^{*} P<0.001$ between sham and ovariectomized mice as evaluated by a Kruskal-Wallis nonparametric test.

taneous blockade of both IL- 1 and TNF $\alpha$, perhaps reflecting a requirement for both cytokines to stimulate rapid osteoclast activation and thus increased bone resorption $(27,28)$. Whether TNF $\alpha$ and IL-1 may act directly on mature osteoclasts has, however, not yet been shown. On the other hand, production of osteoclasts (osteoclastogenesis) is a process in which it has been proposed that IL-1 and TNF $\alpha$ may act synergistically, since either TNF $\alpha$ or IL-1 blockade appears to decrease osteoclastogenesis after ovariectomy $(18,27,28)$. It has also been proposed that this latter effect of IL-1 and TNF $\alpha$ is mediated by IL-6 $(10,13)$, a cytokine which promotes the proliferation of bone-marrow cells. Osteoclasts derive from bonemarrow along the macrophage-differentiation pathway, and require for differentiation the action of M-CSF; a mutation in the M-CSF gene results into the op/op phenotype in mice, which is characterized by severe depletion in macrophage and osteoclasts, and by markedly impaired bone resorption (29). TNF $\alpha$ and IL-1 are capable of inducing a marked synthesis of IL-6 by a variety of cells, including osteoblasts, an effect which

\section{Control Mice}

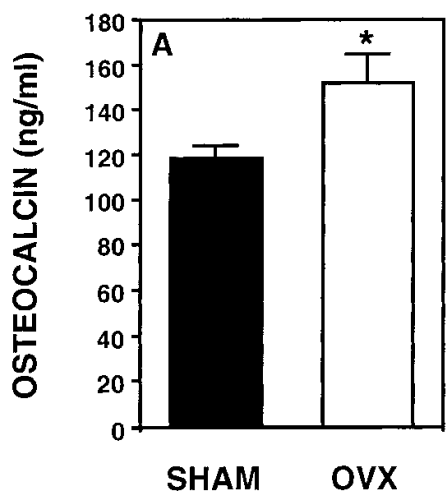

Transgenic Mice

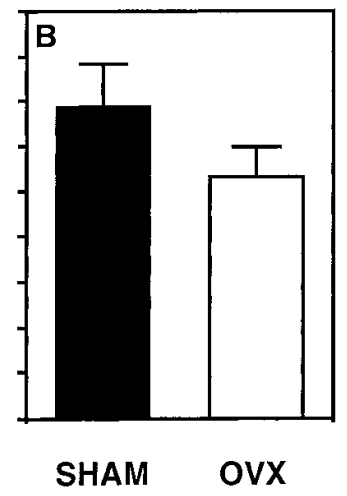

Figure 2. Plasma osteocalcin $(\mathrm{ng} / \mathrm{ml})$ in control $(A)$, or in transgenic mice $(B) 12 \mathrm{wk}$ after ovariectomy (OVX) or sham-operation. Values are means \pm SEM, $n=3-4$. Significance of difference between groups was evaluated with a two-sided Student's $t$ test. is decreased by estrogen addition in vitro $(10,11)$. It has been reported that bone-marrow and bone cells of ovariectomized mice release increased amounts of IL-6 in vitro. Mutant mice lacking a functional IL- 6 gene do not show bone loss nor any increase in osteoclasts or their precursors one month after ovariectomy (30). This is consistent with the possibility that IL-6 acts downstream of TNF $\alpha$ in the accelerated bone loss due to estrogen depletion, and would thus be an essential mediator of osteoclastogenesis (13). This interpretation, however, is hampered by the possibility that IL-6-deficient mice may have intrinsic bone remodeling defects preexisting to ovariectomy. It has been reported in this respect that treatment of normal ovariectomized mice with anti IL- 6 antibody did not decrease bone resorption (31). Furthermore, in vitro studies have shown that IL-6 did indeed induce osteoclast differentiation, but by an autocrine action on osteoblasts rather than by a direct action on osteoclast progenitors (32). Thus, TNF $\alpha$ may participate without IL-6 mediation to osteoclastogenesis and osteoclast maturation, since it induces the release of M-CSF by osteoblastic cell lines (33) and is known to exert differentiation-inducing effects on macrophages, including its own release and that of M-CSF by macrophages themselves $(34,35)$. An additional "downstream" effect of TNF $\alpha$ facilitating osteoclasts maturation, directly or through M-CSF release, may thus also be involved in bone loss resulting from estrogen deficiency. Under these conditions, our transgenic mice should prove highly useful to further clarify the chain of events leading to increased osteoclastogenesis in estrogen deficiencyinduced osteoporosis. While there is evidence that TNF, IL-1, and IL- 6 are involved in the very complex pathway operating in bone remodeling, and show a considerable degree of interplay, it appears from the present work that at least TNF $\alpha$ is required in remodelling occurring after estrogen depletion.

In conclusion, transgenic mice unable to use TNF $\alpha$ because of the expression of large amounts of soluble $\mathrm{TNF} \alpha$-receptor in the circulation are comparable to their non transgenic littermates in the development, the amount and mechanical quality of bone. This indicates that $\mathrm{TNF} \alpha$ does not play a major regulating role in normal bone growth and modeling, or that its action can be replaced by that of other cytokines. These transgenic mice, however, appear protected against loss of trabecular bone and increased in bone remodeling resulting from ovariectomy. This suggests that an increment in TNF $\alpha$ production resulting from estrogen deficiency plays a critical role in the induction of increased bone turnover.

\section{Acknowlegments}

We thank Dr. D. Chappard for his help in analyzing the histomorphometric data; Mrs. P. Chabert, C. Godin, and I. Georges for their expert technical assistance; P. Michel for mouse breeding; C. Ang for typing; and Dr. Ann Kato for reading the manuscript.

This project was supported by grants from the Swiss National Science Foundation (Grant 32-32415-91, 31-37516-93, and 31-42275-94). R. Rizzoli was a recipient of a Max Cloetta Foundation career development award and I. Garcia was supported by a Marie-Heim Vögtlin Grant (32-41729-94).

\section{References}

1. Bertolini, D.R., G.E. Nedwin, T.S. Bringman, D.D. Smith, and G.R. Mundy. 1986. Stimulation of bone resorption and inhibition of bone formation in vitro by human tumor necrosis factors. Nature (Lond.). 319:516-518. 
2. Chaudhary, L.R., T.C. Spelsberg, and B.L.P. Riggs. 1992. Production of various cytokines by normal human osteoblast-like cells in response to interleukin- $1 \beta$ and tumor necrosis factor- $\alpha$ : lack of regulation by $17 \beta$-estradiol. Endocrinology. 130:2528-2534.

3. Johnson, R.A., B.F. Boyce, G.R. Mundy, and G.D. Roodman. 1989. Tumors producing human tumor necrosis factor induce hypercalcemia and osteoclastic bone resorption in nude mice. Endocrinology. 124:1424-1427.

4. Parfitt, A.M. 1994. Osteonal and hemi-osteonal remodeling: the spatial and temporal framework for signal traffic in adult human bone. J. Cell. Biochem. 55:273-286.

5. Riggs, B.L. and L.J. Melton III. 1986. Involutional osteoporosis. N. Engl. J. Med. 314:1676.

6. Kalu, D.N. 1991. The ovariectomized rat model of postmenopausal bone loss. Bone Miner. 15:175-191.

7. Miller, S.C., and T.J. Wronski. 1992. Long-term osteopenic changes in cancellous bone structure in ovariectomized rats. Anat. Rec. 236:433-441.

8. Peck, W.A., P. Burckhardt, C. Christiansen, H.A. Fleisch, H.K. Genant, C. Gennari, T.J. Martin, L. Martini, R. Morita, E. Ogata, A. Rapado, I. Shulman, P.H. Stern, and R.T.T. Young. 1993. Consensus development conference Diagnosis, prophylaxis, and treatment of osteoporosis - rapid publication. Am. J. Med. 94:646-650.

9. Black, K., I.R. Garrett, and G.R. Mundy. 1991. Chinese hamster ovarian cells transfected with the murine interleukin- 6 gene cause hypercalcemia as well as cachexia, leukocytosis and thrombocytosis in tumor-bearing nude mice. Endocrinology. 128:2657-2659.

10. Jilka, R.L., G. Hangoc, G. Girasole, G. Passeri, D.C. Williams, J.S. Abrams, B. Boyce, H. Broxmeyer, and S.C. Manolagas. 1992. Increased osteoclast development after estrogen loss: mediation by interleukin-6. Science (Wash. DC). 257:88-91.

11. Girasole, G., R.L. Jilka, G. Passeri, S. Boswell, G. Boder, D.C. Williams, and S.C. Manolagas. 1992. $17 \beta$ estradiol inhibits interleukin-6 production by bone marrow-derived stromal cells and osteoblasts in vitro: a potential mechanism for the antiosteoporotic effect of estrogens. J. Clin. Invest. 89:883-891.

12. Horowitz, M.C. 1993. Cytokines and estrogen in bone: anti-osteoporotic effects. Science (Wash. DC). 260:626-627.

13. Manolagas, S.C., and R.L. Jilka. 1995. Bone marrow, cytokines, and bone remodeling. Emerging insights into the pathophysiology of osteoporosis. N. Engl. J. Med. 332:305-311.

14. Mundy, G.R. 1992. Effects of TNF on bone and cartilage. In Tumor Necrosis Factors: The Molecules and Their Emerging Role in Medicine. B. Beutler, editor. Raven Press, Ltd. New York. 107-116.

15. Pacifici, R., L. Rifas, R. McCracken, I. Vered, C. McMurtry, L.V. Avioli, and W.A. Peck. 1989. Ovarian steroid treatment blocks a postmenopausal increase in blood monocyte interleukin 1 release. Proc. Natl. Acad. Sci. USA. 86:2398-2402.

16. Pacifici, R., C. Brown, E. Puscheck, E. Friedrich, E. Slatopolsky, D. Maggio, R. McCracken, and L. Avioli. 1991. Effect of surgical menopause and estrogen replacement on cytokine release from human blood mononuclear cells. Proc. Natl. Acad. Sci. USA. 88:5134-5138.

17. Pacifici, R., J.L. Vannice, L. Rifas, and R.B. Kimble. 1993. Monocytic secretion of interleukin-1 receptor antagonist in normal and osteoporotic women: effects of menopause and estrogen/progesterone therapy. J. Clin. Endocrinol. Metab. 77:1135-1141.

18. Kimble, R.B., J.L. Vannice, D.C. Bloedow, R.C. Thompson, W. Hopfer, V.T. Kung, C. Brownfield and R. Pacifici. 1994. Interleukin-1 receptor antagonist decreases bone loss and bone resorption in ovariectomized rats. J. Clin. Invest. 93:1959-1967.
19. Garcia, I., Y. Miyazaki, K. Araki, R. Lucas, G.E. Grau, G. Milon, Y. Belkaid, C. Montixi, W. Lesslauer, and P. Vassalli. 1995. Transgenic mice expressing high levels of soluble TNF-R1 fusion protein are protected from lethal septic shock and cerebral malaria, and are highly sensitive to Listeria monocytogenes and Leishmania major infections. Eur. J. Immunology 25:2401-2407.

20. Ammann, P., R. Rizzoli, D. Slosman, and J.P. Bonjour. 1992. Sequential and precise in vivo measurement of bone mineral density in rats using dualenergy X-ray absorptiometry. J. Bone Miner. Res. 7:311-316.

21. Ammann, P., R. Rizzoli, J.-M. Meyer, and J.-P. Bonjour. 1996. Bone density and shape as determinants of bone strength in IGF-I and/or pamidronate-treated ovariectomized rats. Osteoporosis Int. 6:219-227.

22. Bourrin, S., S. Palle, R. Pupier, L. Vico, and C. Alexandre. 1995. Effects of physical training on bone adaptation in three zones of the rat tibia. J. Bone Miner. Res. 10: 1745-1752.

23. Parfitt, A.M. 1987. Bone histomorphometry: standardization of nomenclature, symbols and units. J. Bone Miner. Res. 2:595-610.

24. Parfitt, A.M. 1983. Stereologic basis of bone histomorphometry: theory of quantitative microscopy and reconstruction of the third dimension. In Bone Histomorphometry: Techniques and Interpretation. R.R. Recker, editor. CRC Press, Boca Raton, FL. 53-89.

25. Chen, P.S., T.Y. Toribara, and H. Warner. 1956. Microdetermination of phosphorus. Anal. Chem. 28:1756.

26. Gentile, M., R. Balena, H. Chen, and G.A. Rodan. 1995. Interleukin-1 beta gene deletion ("knock-out") does not reduce bone loss in ovariectomized mice. J. Bone Miner. Res. 10:s364.

27. Kitazawa, R., R.B. Kimble, J.L. Vannice, V.T. Kung, and R. Pacifici. 1994. Interleukin-1 receptor antagonist and tumor necrosis factor binding protein decrease osteoclast formation and bone resorption in ovariectomized mice. J. Clin. Invest. 94:2397-2406.

28. Kimble, R.B., A.B. Matayoshi, J.L. Vannice, V.T. Kung, C. Williams, and R. Pacifici. 1995. Simulatneous block of interleukin-1 and tumor necrosis factor is required to completely prevent bone loss in the early postovariectomy period. Endocrinology. 136:3054-3061.

29. Felix, R., M.G. Cecchini, and H. Fleisch. 1990. Macrophage colony stimulating factor restores in vivo bone resorption in the OP/OP osteopetrotic mouse. Endocrinology. 127:2592-2594.

30. Poli, V., R. Balena, E. Fattori, A. Markatos, M. Yamamoto, H. Tanaka, G. Ciliberto, G.A. Rodan, and F. Costantini. 1994. Interleukin-6 deficient mice are protected from bone loss caused by estrogen depletion. EMBO (Eur. Mol. Biol. Organ.) J. 13:1189-1196.

31. Kimble, R.B., S.D. Bain, V. Kung, and R. Pacifici. 1995. Inhibition of IL-6 activity in genetically normal mice does not prevent ovariectomy-induced bone loss. J. Bone Miner. Res. 10:S160.

32. Udagawa, N., N. Takahashi, T. Katagiri, T. Tamura, S. Wada, D.M. Findlay, T.J. Martin, H. Hirota, T. Tada, T. Kishimoto, and T. Suda. 1995. Interleukin (IL-6) induction of osteoclast differentiation depends on IL-6 receptors expressed on osteoblastic cells but not on osteoclast progenitors. J. Exp. Med. 182:1461-1468.

33. Felix, R., M.G. Cecchini, W. Hofstetter, H.L. Guenther, and H. Fleisch. 1991. Production of granulocyte-macrophage (GM-CSF) and granulocyte colony-stimulating factor (G-CSF) by rat clonal osteoblastic cell line IRC 10/30 myc1 stimulated by tumor necrosis factor-alpha. Endocrinology. 128:661-667.

34. Vassalli, P. 1992. The pathophysiology of tumor necrosis factors. Annu. Rev. Immunol. 10:411-452.

35. Yamada, H., S. Iwase, M. Mohri, and D. Kufe. 1991. Involement of a nuclear factor-kappa B-like protein in induction of the macrophage colony-stimulating factor gene by tumor necrosis factor. Blood. 78 (8):1988-1995. 